Department of Social Systems and Management

\author{
Discussion Paper Series
}

No. 1128

Measuring the Change in R\&D Efficiency of the Japanese Pharmaceutical Industry

by

Akihiro Hashimoto and Shoko Haneda

July 2005

UNIVERSITY OF TSUKUBA

Tsukuba, Ibaraki 305-8573

JAPAN 


\title{
MEASURING THE CHANGE IN R\&D EFFICIENCY OF THE JAPANESE PHARMACEUTICAL INDUSTRY
}

\author{
AKIHIRO HASHIMOTO ${ }^{a, *}$ and SHOKO HANEDA ${ }^{\mathrm{b}, \dagger}$ \\ ${ }^{a}$ Graduate School of Systems and Information Engineering, University of Tsukuba, Tsukuba, \\ Ibaraki 305-8573, Japan; ${ }^{\mathrm{b}}$ Faculty of Business Administration, Komazawa University, \\ Komazawa, Setagaya, Tokyo 154-8525, Japan
}

\begin{abstract}
This paper presents a DEA (Data Envelopment Analysis)/ Malmquist index methodology for measuring the R\&D efficiency change of the Japanese pharmaceutical industry. Letting each of ten firms each year be a separate DMU (Decision-Making Unit) and employing one input and three outputs in the DEA, and using the cumulative frontier shift component on average proposed in the Malmquist index analysis, we quite obviously show the industry-wide R\&D efficiency change for the period 1982-2001. The results empirically reveal that the R\&D efficiency of the Japanese industry, which has seemed elusive, has surely gotten worse almost monotonically for these twenty years at least as to the pharmaceutical one.
\end{abstract}

Keywords: R\&D efficiency change; Data envelopment analysis; Malmquist index; Japanese pharmaceutical industry

JEL Classification: O32, C61, L65

\section{INTRODUCTION}

This paper measures R\&D efficiency of Japanese pharmaceutical firms and examines how $R \& D$ efficiency at the industry level has changed over time. $R \& D$ in firms, that can be considered as a stage prior to production, would be as important as production. But we have not quantitatively analyzed R\&D efficiency so much as productivity. The lack of how to measure R\&D efficiency would be the main reason. In considering the input and output of $R \& D$, we cannot immediately specify what to be as the output, compared with R\&D investment as the input. Geisler (1995) and Brown and Svenson (1998) list published articles, patents, new products, etc. as the output. This multiplicity of the output prevents from analyzing $R \& D$ efficiency by means of the ordinary production function, i.e., parametric, approach. After all, true efficiency in R\&D has yet been elusive.

\footnotetext{
${ }^{*}$ Corresponding author. E-mail: hashimot@sk.tsukuba.ac.jp

${ }^{\dagger}$ E-mail shaneda@komazawa-u.ac.jp
} 
Thus it is not easy to measure R\&D efficiency, so that we have seldom observed its chronological transition at the industry level. Has it gradually gotten better as incorporating some innovations into process like productivity could be expected? For the recent Japanese industry, it might not or might have even worsened (Sakakibara and Tsujimoto, 2003). For also the pharmaceutical industry in the world, it is said that the R\&D efficiency is recently in decline (Tollman et al., 2004). Taking up the Japanese pharmaceutical industry, we verify whether the R\&D efficiency has gotten better or worse for the latest twenty years.

In order to analyze the R\&D efficiency, we employ DEA (Data Envelopment Analysis) (e.g., Charnes et al., 1994, Cooper et al., 2000). DEA is a non-parametric method that can measure the relative efficiency, i.e., DEA efficiency, of objects called DMUs (DecisionMaking Units) with multiple inputs and multiple outputs. Although DEA could be applied to various fields other than the standard efficiency analysis (e.g., Hashimoto and Ishikawa, 1993, Hashimoto, 1996), the DEA characteristic that can deal with even multiple outputs has enabled to measure the efficiency of a variety of DMU sets in also the original efficiency analysis. For example, Nasierowski and Arcelus (2003) recently measure the efficiency of 45 national innovation systems with two inputs and three outputs using DEA. However, we can find no DEA analyses of firms' R\&D efficiency except for Honjo and Haneda (1998). They try to analyze the R\&D efficiency of fourteen Japanese pharmaceutical firms with one input and two outputs for the period 1977-1991. Refining their analyses, we also preparatorily do DEA analyses using the panel data of ten pharmaceutical firms for 19822001. But we should note that the ordinary DEA cannot analyze as taking the $D E A$ efficiency frontier shifting over time into consideration.

Then, we introduce DEA/ Malmquist index analysis (e.g., Färe et al., 1998, Thanassoulis, 2001) to examine time series change in $R \& D$ efficiency at the industry level. The Malmquist index can measure the ratio of DEA efficiencies in two different time periods with shifting DEA efficiency frontiers. Although we recently have some DEA/ Malmquist index applications, most of which are applied to productivity like González and Gascón (2004). The Malmquist index can be decomposed into two components: "catch-up" and "frontier shift". The former measures how much closer to the frontier a DMU, i.e., a firm, moves, while the latter does the movement of the frontier. Since the frontier is composed of the DEA efficient DMUs among all the firms in a time period, the frontier shift means the change at the industry level, not at the firm one. Using this frontier shift, we devise to quite obviously display the R\&D efficiency change of the Japanese pharmaceutical industry for the period 1982-2001.

\section{DATA TO MEASURE R\&D EFFICIENCY}

To DEA-analyze the R\&D efficiency and its change of the Japanese pharmaceutical industry, we provide four data panels as follows: Each panel is ten firms $\times$ twenty years. That is, the sample period is the latest 1982-2001 and the ten pharmaceutical firms are Takeda, Sankyo, Yamanouchi, Daiichi, Eisai, Shionogi, Fujisawa, Chugai, Tanabe and Yoshitomi. They are all big enterprises driving $R \& D$ and seem homogeneous as professional-medicine makers. Although we first took the biggest thirteen pharmaceutical firms of Japan into consideration, Kyowa-Hakko and Meiji-Seika were excluded because each of their medicine sales did not reach to fifty percent of its whole sales. We also excluded Taisho because of its characteristic as a popular-medicine maker peculiar vs the other firms.

DEA relatively evaluates how efficiently DMUs convert multiple inputs into multiple 
outputs. That is, any DMU producing more outputs with fewer inputs is judged relatively efficient. In DEA-analyzing the R\&D efficiency of pharmaceutical firms as the DMUs, we can straightforward list $R \mathscr{E} D$ expenditure (billion yen a year) as the input. As the multiple outputs, we consider the following three: We first list patents (the number of patent applications publicly published a year) as a proxy of invention. R\&D activities in firms can be divided into two: one aiming at "product innovation" and the other aiming at "process innovation". While the former contributes sales increase through product discrimination, the latter does profit increase through cost reduction (Odagiri, 1987). Corresponding to these respectively, we list pharmaceutical sales (ten billion yen a year) and operating profit (billion yen a year) as the additional outputs.

We collect annual data to the one input and three outputs, for the ten firms in the period 1982-2001, from Data Book (Tokyo: Japan Pharmaceutical Manufacturers Association) and NEEDS Database (Tokyo: Nihon Keizai Shimbun, Inc.). The four indicators except for patents are all deflated to the 2001 value.

\section{PRELIMINARY DEA ANALYSES OF R\&D EFFICIENCY}

We here apply the data collected to a DEA model measuring the relative DEA efficiency of target DMU $j_{0}, h_{j_{0}}\left(0 \leq h_{j_{0}} \leq 1\right)$. We employ the $C C R$ (Charnes, Cooper and Rhodes, 1978) model, and its input-oriented and envelopment form is formulated as the following LP (Linear Programming):

$$
\begin{aligned}
\text { Minimize } & h_{j_{0}}=\theta-\epsilon\left(\sum_{r=1}^{t} s_{r}^{+}+\sum_{i=1}^{m} s_{i}^{-}\right)=\theta-\epsilon \sigma \\
\text { subject to } & \sum_{j=1}^{n} \lambda_{j} y_{r j}-s_{r}^{+}=y_{r j_{0}}, r=1, \ldots, t, \\
& \sum_{j=1}^{n} \lambda_{j} x_{i j}-\theta x_{i j_{0}}+s_{i}^{-}=0, i=1, \ldots, m, \\
& \lambda_{j}, s_{r}^{+}, s_{i}^{-} \geq 0, j=1, \ldots, n, r=1, \ldots, t, i=1, \ldots, m, \\
& (\theta \text { unconstrained }),
\end{aligned}
$$

where $\theta, \lambda_{j}, s_{r}^{+}, s_{i}^{-}=$decision variables to LP, $y_{r j}=$ the amount of output $r$ from DMU $j, x_{i j}=$ the amount of input $i$ to DMU $j, n=$ the number of DMUs, $t=$ the number of outputs, $m=$ the number of inputs, $\epsilon=$ a positive non-Archimedean infinitesimal. We can find DEA efficiencies of all the DMUs by solving LP (1) $n$ times, setting each DMU as target DMU $j_{0}$ in turn. Here, DMU $j_{0}$ with the minimum $h_{j_{0}}^{*}=1$ is judged $D E A$ efficient, but DMU $j_{0}$ with $h_{j_{0}}^{*}=1-\epsilon \sigma^{*}\left(\sigma^{*} \neq 0\right) \cong 1$ can be discriminated as "weakly DEA efficient".

Three preliminary DEA analyses of the ten pharmaceutical firms are shown in Appendix. We should note the following: First, we employ the CCR model assuming the constant returns-to-scale, not the variable returns-to-scale, because the ten sample firms are all big enterprises and can be regarded comparable under the assumption (see Appendix). Second, as data measuring the R\&D efficiency, we apply input and output data of the same year, not using the input data of a year together with the output data of some years later. Surely, the effect of input would emerge on the output some time later. However, we have no knowledge of how the delay is. Therefore, we might had better consider 
that the $R \& D$ efficiency measured here means the efficiency of rather the R\&D sector in firms, that must be settled an account by the annual data, than the R\&D activity itself.

From the results of DEA analyses, the R\&D efficiency of Japanese pharmaceutical firms do not seem to have gotten better for the period 1982-2001 at all. But these analyses are all at the firm level, and cannot exactly grasp how the R\&D efficiency of the pharmaceutical industry has changed in this period. This is a limit of the ordinary DEA single-handed analyses.

\section{CHANGE IN R\&D EFFICIENCY FOR 1982-2001}

To quantitatively show the R\&D efficiency change of the industry for 1982-2001, we here introduce the DEA/ Malmquist index analysis and apply the same data collected.

\subsection{DEA/ Malmquist Index Analysis}

DEA/ Malmquist index analysis measures the Malmquist (productivity) index (Malmquist, 1953, Caves et al., 1982) in the DEA frame:

In Figure 1, a single input and output DEA case, DMU $j_{0}$ being evaluated was at point A in period $\alpha$ and line OCD shows the then CCR DEA efficiency frontier. Suppose that in period $\beta(\beta>\alpha)$, DMU $j_{0}$ has moved to point $\mathrm{B}$ and the frontier itself has also shifted to line OEF. DEA efficiency change of DMU $j_{0}$ can be measured by the ratio of DEA efficiency in period $\beta$ to that in period $\alpha$, but the frontier has shifted, so that we compute the geometric mean of ratios as to the two frontiers in periods $\alpha$ and $\beta$. This is the DEA (CCR input oriented)/ Malmquist index of DMU $j_{0}$ between periods $\alpha$ and $\beta$

$$
M I_{j_{0}}[\alpha, \beta] \equiv\left(\frac{Q D / Q B}{P C / P A} \cdot \frac{Q F / Q B}{P E / P A}\right)^{1 / 2}
$$

Here, $M I>1$ means gain in DEA efficiency of DMU $j_{0}$ from period $\alpha$ to $\beta$, while $M I=1$ and $M I<1$ mean the status quo and loss respectively.

Transforming formula (2), Malmquist index can be decomposed into two components as follows:

$$
\begin{aligned}
M I_{j_{0}}[\alpha, \beta] & =\frac{Q F / Q B}{P C / P A} \times\left(\frac{P C}{P E} \cdot \frac{Q D}{Q F}\right)^{1 / 2} \\
& =C U_{j_{0}}[\alpha, \beta] \times F S_{j_{0}}[\alpha, \beta] \\
& =\frac{Q F / Q B}{P C / P A} \times\left(\frac{P C / P A}{P E / P A} \cdot \frac{Q D / Q B}{Q F / Q B}\right)^{1 / 2} .
\end{aligned}
$$

As each term of formula (3) shows, $C U$ indicates Catch- $U p$ index, i.e, $C U>1$ means that DMU $j_{0}$ has moved closer to the period $\beta$ frontier than to the period $\alpha$ one. $C U=1$ and $C U<1$ mean that it has the same distance and that it has moved farther, respectively. $F S$ indicates Frontier Shift index, and FS $>1$ means gain in DEA efficiency frontier shift from period $\alpha$ to $\beta$ measured from the location of DMU $j_{0}$, i.e., the frontier has moved so as to have the more output with the fewer input as shown in Figure 1. FS $=1$ and $F S<1$ mean no change and loss respectively.

Since $P E / P A$ in Figure 1 is, for example, the (radial) DEA efficiency of the period $\alpha$ DMU $j_{0}$ measured by means of the period $\beta$ frontier, we denote it as $\theta\left[D^{\alpha}, F^{\beta}\right]$. Then 
from formula (4),

$$
M I_{j_{0}}[\alpha, \beta]=\frac{\theta\left[D^{\beta}, F^{\beta}\right]}{\theta\left[D^{\alpha}, F^{\alpha}\right]} \times\left(\frac{\theta\left[D^{\alpha}, F^{\alpha}\right]}{\theta\left[D^{\alpha}, F^{\beta}\right]} \cdot \frac{\theta\left[D^{\beta}, F^{\alpha}\right]}{\theta\left[D^{\beta}, F^{\beta}\right]}\right)^{1 / 2} .
$$

In LP (1), ignoring the infinitesimal term, regarding $s_{r}^{+}$and $s_{i}^{-}$as slack variables, denoting $y_{j}=\left[y_{1 j}, \ldots, y_{t j}\right], x_{j}=\left[x_{1 j}, \ldots, x_{m j}\right]$ and letting $x_{j}^{\alpha}=x_{j}$ in period $\alpha, \theta\left[D^{\alpha}, F^{\alpha}\right]$ can be obtained as the minimum of the following LP, the ordinary DEA model:

$$
\begin{aligned}
\text { Minimize } & \theta \\
\text { subject to } & \sum_{j=1}^{n} \lambda_{j} y_{j}^{\alpha} \geq y_{j_{0}}^{\alpha}, \\
& \sum_{j=1}^{n} \lambda_{j} x_{j}^{\alpha}-\theta x_{j_{0}}^{\alpha} \leq 0, \\
& \lambda_{j} \geq 0, j, \ldots, n, \\
& (\theta \text { unconstrained }) .
\end{aligned}
$$

$\theta\left[D^{\beta}, F^{\beta}\right]$ can also be obtained by the LP (6) replaced $\alpha$ by $\beta$.

While $\theta\left[D^{\alpha}, F^{\beta}\right]$ is obtained as the minimum of

$$
\begin{aligned}
\text { Minimize } & \theta \\
\text { subject to } & \sum_{j=1}^{n} \lambda_{j} y_{j}^{\beta} \geq y_{j_{0}}^{\alpha}, \\
& \sum_{j=1}^{n} \lambda_{j} x_{j}^{\beta}-\theta x_{j_{0}}^{\alpha} \leq 0, \\
& \lambda_{j} \geq 0, j, \ldots, n, \\
& (\theta \text { unconstrained }),
\end{aligned}
$$

this forms the DEA exclusion model (Andersen and Petersen, 1993). Finally, we can obtain $\theta\left[D^{\beta}, F^{\alpha}\right]$ by also the DEA exclusion model (7) exchanged $\alpha$ and $\beta$.

\subsection{Cumulative Malmquist Index}

Applying the data to models (6) and (7), and through formula (5), we can compute the catch-up $C U_{j_{0}}[\alpha, \beta]$, the frontier shift $F S_{j_{0}}[\alpha, \beta]$ and the Malmquist $M I_{j_{0}}[\alpha, \beta]$ indices. These indices for a year are usually compared to the preceding year. However, such successive indices do not seem appropriate to grasp the chronological change for twenty years in the wide range of vision. Therefore, we propose to employ another index than the successive one. Tables 1-3 respectively show $M I_{j_{0}}[1982, \beta], C U_{j_{0}}[1982, \beta]$ and $F S_{j_{0}}[1982, \beta]$, $\beta=1982, \ldots, 2001$. They are all compared to the start year 1982. Since they involve their successive changes up to year $\beta$, we call them cumulative indices. The cumulative index values when $\beta=1982$ could be considered 1. Since the Malmquist index is multiplicative, we here employ geometric means, not arithmetic ones, as all the averages.

The Malmquist index indicates the R\&D efficiency change of a firm taking the $R \& D$ efficiency frontier shifting into consideration. Thus Table 1 shows that the R\&D efficiency of Japanese pharmaceutical firms has gotten worse in average at the annual rate $4.7 \%$ for 1982-2001, and has in year 2001 dropped to under $40 \%$ of the start year 1982 . This implies a big loss in firms' R\&D efficiency. We should note that all the ten firms have 
this decreasing R\&D efficiency. The worst for this period would be Chugai and Fujisawa while the last worst, Takeda. Since the annual catch-up rate on average in Table 2 is 0.993 (nearly 1), we find that the Malmquist (Table 1) would depend much more on the frontier shift (Table 3) than the catch-up (Table 2).

The catch-up measures how much closer to the yearly R\&D efficiency frontier a firm moves. For only the catch-up, Takeda, Daiichi and Tanabe have gotten even better for this period (Table 2). The cumulative catch-up is the ratio of $R \& D$ efficiency of a firm in year $\beta$ to that in year 1982. Therefore, in Table A1, the cross-section DEA efficiency of a year divided by that of year 1982 is the catch-up value of the year in Table 2. That is, for Sankyo, the values in Tables 2 and A1 are equal, and for Daiichi, for example, the values in Table 2 do not exceed $1 / 0.67=1.501$, i.e., its upper limit.

Picking up columns from Tables 1-3, we can draw a graph of the three cumulative indices for each firm. Figure 2 for Sankyo and Figure 3 for Daiichi are examples: In Figure 2, the catch-up shows that Sankyo has been on the R\&D efficiency frontier from the start year 1982 to 1998 . The Malmquist, that has been equal to the frontier shift for these years, has in year 2001 gone worsened to $25.4 \%$ of the start year. For Daiichi (Figure 3 ), as is mentioned before, the catch-up has gotten better since the start year and it has reached to the upper limit in years 1985-1987 and 1989. The cumulative Malmquist indices are also over 1 for 1985-1989, so that this shows that the R\&D efficiency of Daiichi has improved for this period compared to the start year. In this way, we can quantitatively show the chronological changes in a firm's R\&D efficiency using the three cumulative indices.

\subsection{R\&D Efficiency Loss by the Industry}

The cumulative frontier shift index indicates the move of the industry's $R \& D$ efficiency frontier from the viewpoint (location) of each firm. Therefore, the frontier shift on average (Table 3) could be an appropriate indicator to measure the R\&D efficiency change at the industry level. The annual change rate 0.960 means that the $R \& D$ efficiency of the Japanese pharmaceutical industry has worsened at the annual rate $4.0 \%$ for 1982-2001. That is, the great R\&D efficiency frontier shift reverse to as shown in Figure 1 has occurred.

Figure 4 is a graph of the cumulative frontier shift on average in Table 3 . It shows that the R\&D efficiency of the industry has gotten worse to about $70 \%$ of the start year 1982 just in year 1984, and has finally dropped to $45.8 \%$ in year 2001 via the lowest $38.9 \%$ in 2000. Although there are observed the recoveries in years 1993 and 2001, we must say that the industry's R\&D efficiency has almost monotonically been decreasing throughout the period. Thus, we could quite obviously show how the industry-wide R\&D efficiency has changed, which implies the great loss in R\&D efficiency by the Japanese pharmaceutical industry for the period 1982-2001.

\section{SUMMARY AND CONCLUSIONS}

This study presented a DEA/ Malmquist index methodology for measuring the R\&D efficiency change at the industry level. Using the cumulative frontier shift index proposed in the methodology, we could quantitatively show the time series change in the R\&D efficiency of the Japanese pharmaceutical industry for the period 1982-2001. We here found the great R\&D efficiency loss by the industry throughout the period and that the industry's R\&D efficiency had dropped in year 2001 to even under fifty percent of the start year 1982 . 
Since year 1982, why has annually each firm continued to enormously invest in the R\&D in spite of the decreasing efficiency? Haneda and Odagiri (1998) indicate that R\&D investment affects the value of firm. Because of such factors other than efficiency, the firm might have to continue to invest in R\&D. Whether this is true, and whether the recent loss in R\&D efficiency comes under the other industries are up to the further studies. In also these study fields, the methodology presented in this paper would be valid to examine them.

\section{Appendix}

Solving DEA model (1) with one input and three outputs $(m=1, t=3)$, we obtain DEA efficiencies $h_{j_{0}}^{*}$ shown in Tables A1-A3. In all these Tables, value 1 indicates DEA efficient, including no weakly DEA efficient DMUs. We should here notice rather the location of value 1 than the DEA efficiency values themselves. Table A1 shows the results of twenty DEA cross-section analyses with ten DMUs $(n=10)$, i.e., the cross-section DEA by year, treating each firm as a separate DMU. It is noteworthy that Takeda and Yoshitomi, respectively the largest and the smallest scaled firms measured by the $R \& D$ expenditure, both are judged DEA efficient in multiple time periods. This affirms the employment of CCR model assuming the constant returns-to-scale. We find that Sankyo would have been most efficient in R\&D because it is judged DEA efficient in seventeen years among the twenty. On the contrary, Eisai has never been DEA efficient for these twenty years.

Table A2 shows the results of ten DEA time series analyses with twenty DMUs $(n=$ 20), i.e., the time series DEA (Cooper et al., 1995, Hashimoto and Kodama, 1997) by firm, treating each year as a separate DMU. We find that all the firms have their own DEA efficient years in the first two years, 1982-1983. And only three firms, Takeda, Sankyo and Yoshitomi, have them in also the last half of the period, 1992-2001. There are no firms having them in the third quarter of the period, 1992-1996. Table A3 shows the results of a DEA panel analysis with 200 DMUs $(n=200=10$ firms $\times 20$ years $)$, i.e., the panel DEA treating each firm each year as a separate DMU. We find that the frontier in this DEA is composed of only two DMUs, Sankyo 1982 and Yamanouchi 1988. These are most efficient DMUs among the 200 and both are in the first half of the period.

\section{References}

Andersen, P. and Petersen, N. C. (1993) A Procedure for Ranking Efficient Units in Data Envelopment Analysis. Management Science, 39(10), 1261-1264.

Brown, M. G. and Svenson, R. A. (1998) Measuring R\&D Productivity. Research Technology Management, 41(6), 30-35.

Caves, D. W., Christensen, L. R. and Diewert, W. E. (1982) The Economic Theory of Index Numbers and the Measurement of Input, Output, and Productivity. Econometrica, 50(6), 1393-1414.

Charnes, A., Cooper, W. W. and Rhodes, E. (1978) Measuring the Efficiency of Decision Making Units. European Journal of Operational Research, 2, 429-444.

Charnes, A., Cooper, W. W., Lewin, A. Y. and Seiford, L. M. (eds.) (1994) Data Envelopment Analysis: Theory, Methodology and Application. Boston: Kluwer Academic Publisher. 
Cooper, W. W., Kumbhakar, S., Thrall, R. M. and Yu, X. (1995) DEA and Stochastic Frontier Analyses of the 1978 Chinese Economic Reforms. Socio-Economic Planning Sciences, 29, 85-112.

Cooper, W. W., Seiford, L. M. and Tone, K. (2000) Data Envelopment Analysis: A Comprehensive Text with Models, Applications, References and DEA-Solver Software. Boston: Kluwer Academic Publisher.

Färe, R., Grosskopf, S. and Russell, R. R. (eds.) (1998) Index Numbers: Essays in Honour of Sten Malmquist. Boston: Kluwer Academic Publisher.

Geisler, E. (1995) An Integrated Cost-Performance Model of Research and Development Evaluation. Omega: International Journal of Management Science, 23(3), 281-294.

González, E. and Gascón, F. (2004) Sources of Productivity Growth in the Spanish Pharmaceutical Industry (1994-2000). Research Policy, 33, 735-745.

Haneda, S. and Odagiri, H. (1998) Appropriation of Returns from Technological Assets and the Values of Patents and R\&D in Japanese High-Tech Firms. Economics of Innovation and New Technology, 7, 303-321.

Hashimoto, A. and Ishikawa, H. (1993) Using DEA to Evaluate the State of Society as Measured by Multiple Social Indicators. Socio-Economic Planning Sciences, 27, 257-268.

Hashimoto, A. (1996) A DEA Selection System for Selective Examinations. Journal of the Operations Research Society of Japan, 39(4), 475-485.

Hashimoto, A. and Kodama, M. (1997) Has Livability of Japan Gotten Better for 19561990?: A DEA Approach. Social Indicators Research, 40, 359-373.

Honjo, Y. and Haneda, S. (1998) R\&D Evaluation of Japanese Pharmaceutical Firms Using DEA. (in Japanese) Journal of Science Policy and Research Management, 13(1/2), 96-105.

Malmquist, S. (1953) Index Numbers and Indifference Surfaces. Trabajos de Estadistica, 4, 209-242.

Nasierowski, W. and Arcelus, F. J. (2003) On the Efficiency of National Innovation Systems. Socio-Economic Planning Sciences, 37, 215-234.

Odagiri, H. (1987) Research and Development: What Are the Contributions? (in Japanese) In Shishido, S. et al. (eds.) Shakai Kogaku Gairon II, 171-184, Tokyo: Gakuyo Shobo.

Sakakibara, K. and Tsujimoto, M. (2003) Why did R\&D Productivity of the Japanese Firms Decline? (in Japanese) ESRI Discussion Paper Series, 47, 1-20, Tokyo: Economic and Social Research Institute, Cabinet Office.

Thanassoulis, E. (2001) Introduction to the Theory and Application of Data Envelopment Analysis: A Foundation Text with Integrated Software. Boston: Kluwer Academic Publisher.

Tollman, P., Goodall, S. and Ringel, M. (2004) Rising to the Productivity Challenge: A Strategic Framework for Biopharma. BCG: Focus, 1, 1-12, Tokyo: Boston Consulting Group. 


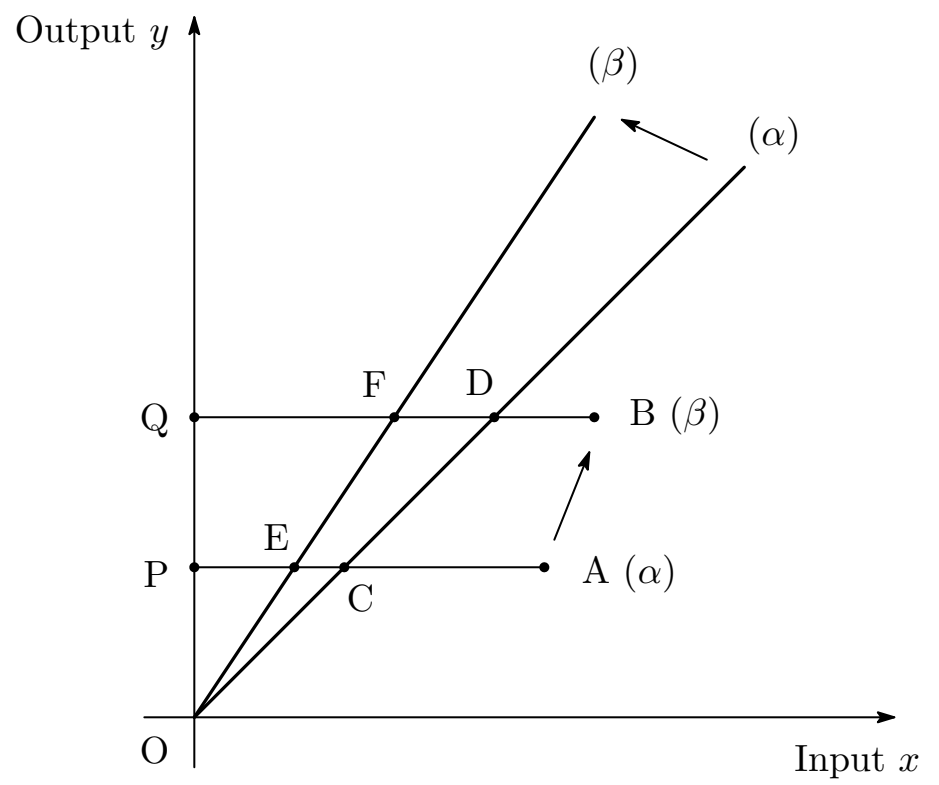

Figure 1. DEA Efficiency Change with the Frontier Shifting over Time. 


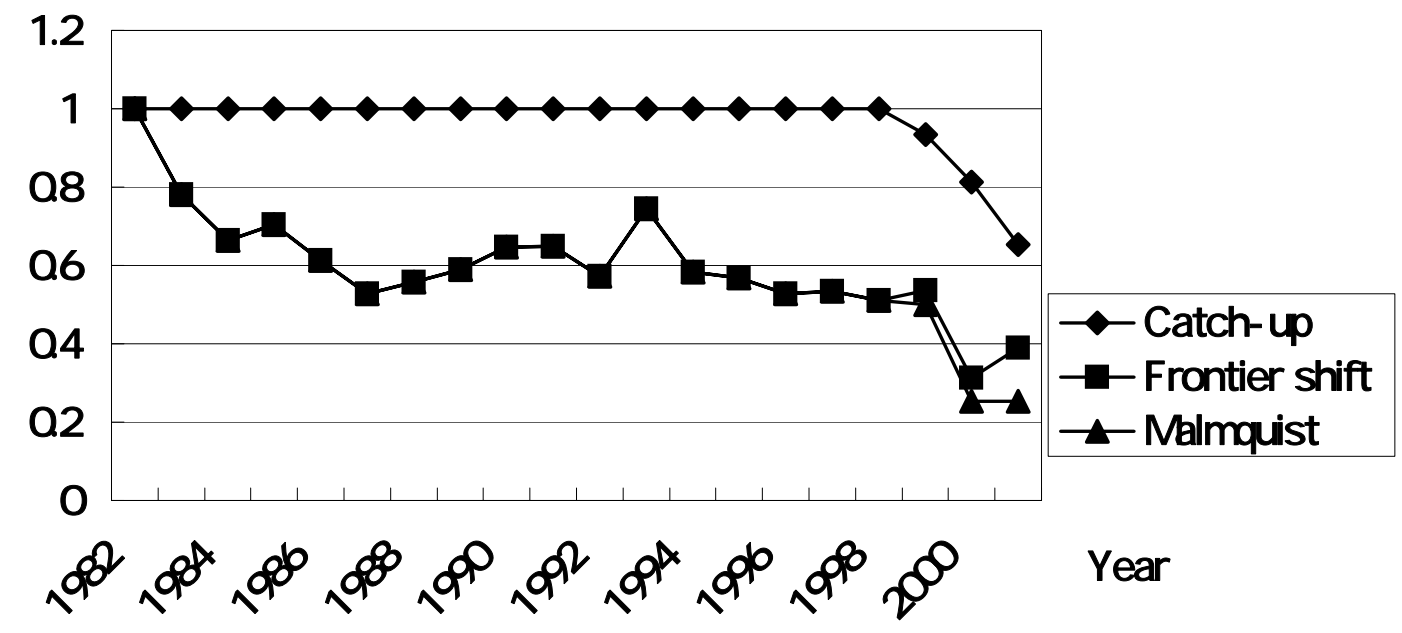

Figure 2. Cumulative Indices for Sankyo. 


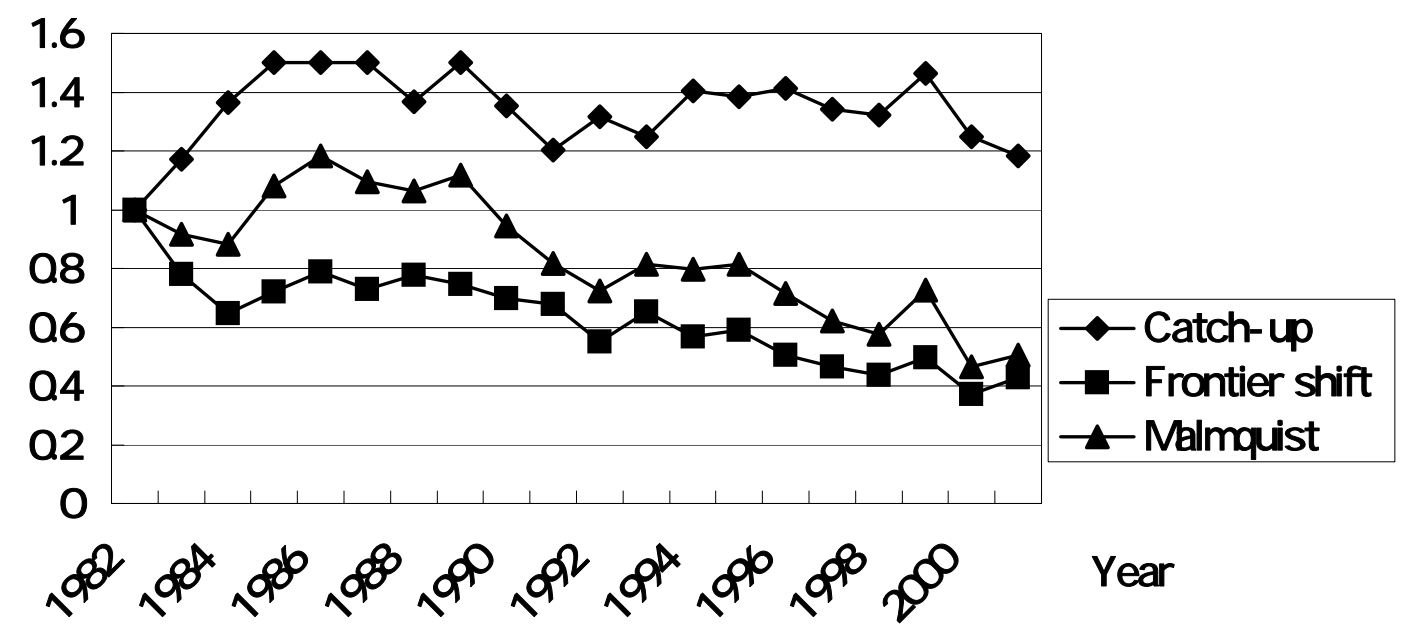

Figure 3. Cumulative Indices for Daiichi. 


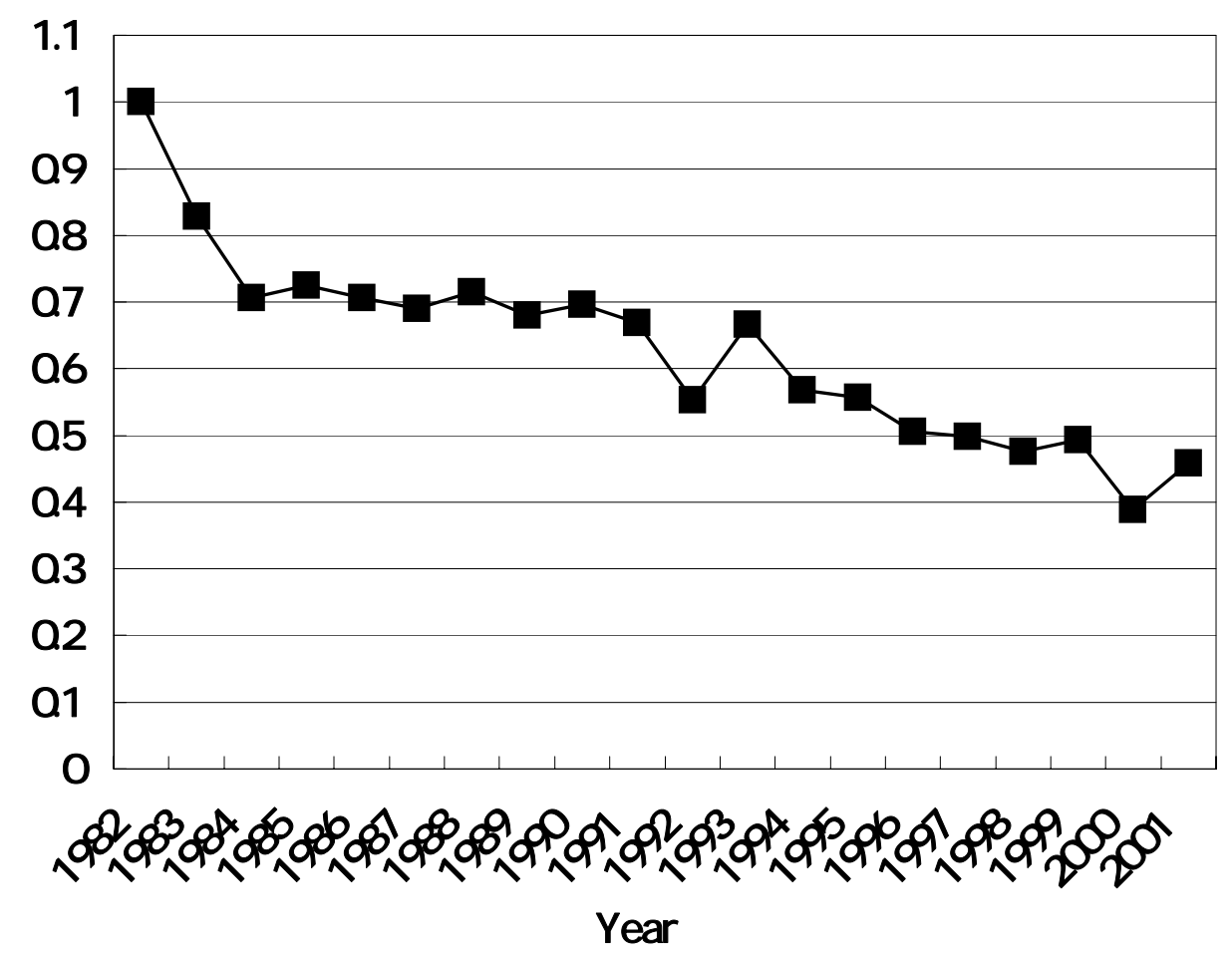

Figure 4. R\&D Efficiency Loss by the Industry for 1982-2001. 
Table 1. Cumulative Malmquist Index $M I_{j o}[1982, \beta$ ], $\beta=1982, \cdots, 2001$

\begin{tabular}{|c|c|c|c|c|c|c|c|c|c|c|c|}
\hline \multirow{2}{*}{$\begin{array}{c}\text { Year } \\
\beta\end{array}$} & \multicolumn{10}{|c|}{ Firm } & \multirow{2}{*}{$\begin{array}{l}\text { Aver- } \\
\text { age }\end{array}$} \\
\hline & Takeda & Sankyo & $\begin{array}{l}\text { Yama } \\
\text { nouchi }\end{array}$ & Daiichi & Eisai & $\begin{array}{l}\text { Shio- } \\
\text { nogi }\end{array}$ & $\begin{array}{l}\text { Fuji- } \\
\text { sawa }\end{array}$ & Chugai & Tanabe & $\begin{array}{l}\text { Yoshi- } \\
\text { tomi }\end{array}$ & \\
\hline 1982 & 1.000 & 1.000 & 1.000 & 1.000 & 1.000 & 1.000 & 1.000 & 1.000 & 1.000 & 1.000 & 1.000 \\
\hline 1983 & 0.897 & 0.781 & 0.852 & 0.915 & 0.862 & 0.870 & 0.827 & 1.043 & 0.877 & 0.656 & 0.853 \\
\hline 1984 & 0.819 & 0.663 & 0.800 & 0.882 & 0.700 & 0.860 & 0.825 & 0.816 & 0.838 & 0.696 & 0.786 \\
\hline 1985 & 0.837 & 0.705 & 0.806 & 1.080 & 0.630 & 0.706 & 0.610 & 0.780 & 0.760 & 0.612 & 0.742 \\
\hline 1986 & 0.811 & 0.613 & 0.748 & 1.184 & 0.718 & 0.747 & 0.731 & 0.704 & 0.953 & 0.501 & 0.752 \\
\hline 1987 & 0.906 & 0.528 & 0.863 & 1.095 & 0.652 & 0.738 & 0.640 & 0.574 & 0.986 & 0.576 & 0.734 \\
\hline 1988 & 0.876 & 0.557 & 0.934 & 1.063 & 0.689 & 0.727 & 0.741 & 0.511 & 0.991 & 0.633 & 0.752 \\
\hline 1989 & 0.747 & 0.590 & 0.888 & 1.118 & 0.718 & 0.668 & 0.650 & 0.494 & 0.711 & 0.910 & 0.731 \\
\hline 1990 & 0.689 & 0.647 & 0.841 & 0.945 & 0.643 & 0.611 & 0.608 & 0.462 & 0.704 & 0.961 & 0.695 \\
\hline 1991 & 0.621 & 0.650 & 0.780 & 0.817 & 0.613 & 0.546 & 0.578 & 0.498 & 0.683 & 0.805 & 0.651 \\
\hline 1992 & 0.614 & 0.573 & 0.638 & 0.724 & 0.567 & 0.524 & 0.558 & 0.458 & 0.670 & 0.531 & 0.581 \\
\hline 1993 & 0.707 & 0.745 & 0.734 & 0.814 & 0.683 & 0.587 & 0.567 & 0.574 & 0.705 & 0.886 & 0.693 \\
\hline 1994 & 0.639 & 0.583 & 0.683 & 0.796 & 0.688 & 0.615 & 0.573 & 0.540 & 0.688 & 0.699 & 0.647 \\
\hline 1995 & 0.770 & 0.567 & 0.685 & 0.815 & 0.681 & 0.613 & 0.554 & 0.501 & 0.638 & 0.720 & 0.648 \\
\hline 1996 & 0.765 & 0.529 & 0.597 & 0.714 & 0.667 & 0.592 & 0.507 & 0.435 & 0.615 & 0.591 & 0.594 \\
\hline 1997 & 0.730 & 0.535 & 0.575 & 0.623 & 0.535 & 0.540 & 0.448 & 0.314 & 0.621 & 0.612 & 0.541 \\
\hline 1998 & 0.811 & 0.511 & 0.395 & 0.576 & 0.411 & 0.521 & 0.391 & 0.334 & 0.549 & 0.540 & 0.489 \\
\hline 1999 & 0.980 & 0.500 & 0.512 & 0.726 & 0.503 & 0.598 & 0.375 & 0.334 & 0.636 & 0.534 & 0.545 \\
\hline 2000 & 0.751 & 0.254 & 0.342 & 0.466 & 0.410 & 0.390 & 0.223 & 0.229 & 0.558 & 0.372 & 0.372 \\
\hline 2001 & 0.915 & 0.254 & 0.358 & 0.506 & 0.462 & 0.460 & 0.234 & 0.230 & 0.654 & 0.316 & 0.398 \\
\hline \multicolumn{12}{|c|}{ Annual change rate } \\
\hline & 0.995 & 0.930 & 0.947 & 0.965 & 0.960 & 0.960 & 0.926 & 0.926 & 0.978 & 0.941 & 0.953 \\
\hline
\end{tabular}


Table 2. Cumulative Catch- Up Index $C U_{j o}[1982, \beta$ ], $\beta=1982, \cdots, 2001$

\begin{tabular}{|c|c|c|c|c|c|c|c|c|c|c|c|}
\hline \multirow{2}{*}{$\begin{array}{c}\text { Year } \\
\beta\end{array}$} & \multicolumn{10}{|c|}{ Firm } & \multirow{2}{*}{$\begin{array}{l}\text { Aver- } \\
\text { age }\end{array}$} \\
\hline & Takeda & Sankyo & $\begin{array}{l}\text { Yama } \\
\text { nouchi }\end{array}$ & Daiichi & Eisai & $\begin{array}{l}\text { Shio- } \\
\text { nogi }\end{array}$ & $\begin{array}{l}\text { Fuji- } \\
\text { sawa }\end{array}$ & Chugai & Tanabe & $\begin{array}{l}\text { Yoshi- } \\
\text { tomi }\end{array}$ & \\
\hline 1982 & 1.000 & 1.000 & 1.000 & 1.000 & 1.000 & 1.000 & 1.000 & 1.000 & 1.000 & 1.000 & 1.000 \\
\hline 1983 & 1.046 & 1.000 & 1.003 & 1.172 & 1.005 & 1.013 & 0.944 & 1.237 & 1.077 & 0.847 & 1.029 \\
\hline 1984 & 1.036 & 1.000 & 1.123 & 1.364 & 0.928 & 1.110 & 1.188 & 1.122 & 1.075 & 1.252 & 1.114 \\
\hline 1985 & 1.128 & 1.000 & 1.123 & 1.501 & 0.840 & 0.917 & 0.859 & 1.031 & 1.003 & 0.969 & 1.023 \\
\hline 1986 & 1.010 & 1.000 & 1.053 & 1.501 & 0.909 & 0.944 & 1.188 & 1.028 & 1.161 & 0.968 & 1.065 \\
\hline 1987 & 1.058 & 1.000 & 1.123 & 1.501 & 0.855 & 0.890 & 0.931 & 0.856 & 1.161 & 1.462 & 1.063 \\
\hline 1988 & 1.006 & 1.000 & 1.123 & 1.366 & 0.817 & 0.868 & 1.025 & 0.846 & 1.161 & 1.488 & 1.051 \\
\hline 1989 & 1.046 & 1.000 & 1.123 & 1.501 & 0.969 & 0.948 & 1.120 & 0.742 & 1.027 & 1.488 & 1.075 \\
\hline 1990 & 0.920 & 1.000 & 1.123 & 1.352 & 0.861 & 0.826 & 1.004 & 0.682 & 0.978 & 1.488 & 0.999 \\
\hline 1991 & 0.906 & 1.000 & 1.094 & 1.202 & 0.831 & 0.740 & 0.996 & 0.774 & 0.910 & 1.488 & 0.974 \\
\hline 1992 & 0.962 & 1.000 & 1.033 & 1.316 & 0.904 & 0.824 & 1.188 & 0.856 & 1.119 & 1.488 & 1.051 \\
\hline 1993 & 1.031 & 1.000 & 0.971 & 1.247 & 0.920 & 0.892 & 1.001 & 0.892 & 1.087 & 1.488 & 1.040 \\
\hline 1994 & 1.035 & 1.000 & 1.100 & 1.404 & 1.053 & 1.065 & 1.142 & 1.039 & 1.161 & 1.488 & 1.139 \\
\hline 1995 & 1.250 & 1.000 & 1.123 & 1.384 & 1.126 & 1.081 & 1.188 & 1.005 & 1.092 & 1.469 & 1.163 \\
\hline 1996 & 1.250 & 1.000 & 1.123 & 1.412 & 1.195 & 1.076 & 1.188 & 1.129 & 1.105 & 1.331 & 1.175 \\
\hline 1997 & 1.250 & 1.000 & 1.120 & 1.341 & 0.923 & 0.980 & 1.053 & 0.739 & 1.153 & 1.488 & 1.085 \\
\hline 1998 & 1.250 & 1.000 & 0.770 & 1.321 & 0.781 & 0.963 & 0.963 & 0.919 & 1.050 & 1.488 & 1.028 \\
\hline 1999 & 1.250 & 0.933 & 1.123 & 1.465 & 1.008 & 1.147 & 1.027 & 0.750 & 1.161 & 1.379 & 1.106 \\
\hline 2000 & 1.250 & 0.813 & 0.836 & 1.249 & 0.878 & 0.905 & 0.744 & 0.634 & 1.161 & 1.413 & 0.958 \\
\hline 2001 & 1.250 & 0.654 & 0.751 & 1.183 & 0.816 & 0.949 & 0.598 & 0.628 & 1.161 & 0.996 & 0.869 \\
\hline \multicolumn{12}{|c|}{ Annual change rate } \\
\hline & 1.012 & 0.978 & 0.985 & 1.009 & 0.989 & 0.997 & 0.973 & 0.976 & 1.008 & 1.000 & 0.993 \\
\hline
\end{tabular}

The upper limit for each firm. 
Table 3. Cumulative Frontier Shift Index $F S_{j o}[1982, \beta], \beta=1982, \cdots, 2001$

\begin{tabular}{|c|c|c|c|c|c|c|c|c|c|c|c|}
\hline \multirow{2}{*}{$\begin{array}{c}\text { Year } \\
\beta\end{array}$} & \multicolumn{10}{|c|}{ Firm } & \multirow{2}{*}{$\begin{array}{l}\text { Aver- } \\
\text { age }\end{array}$} \\
\hline & Takeda & Sankyo & $\begin{array}{l}\text { Yama } \\
\text { nouchi }\end{array}$ & Daiichi & Eisai & $\begin{array}{l}\text { Shio- } \\
\text { nogi }\end{array}$ & $\begin{array}{l}\text { Fuji- } \\
\text { sawa }\end{array}$ & Chugai & Tanabe & $\begin{array}{l}\text { Yoshi- } \\
\text { tomi }\end{array}$ & \\
\hline 1982 & 1.000 & 1.000 & 1.000 & 1.000 & 1.000 & 1.000 & 1.000 & 1.000 & 1.000 & 1.000 & 1.000 \\
\hline 1983 & 0.858 & 0.781 & 0.849 & 0.781 & 0.858 & 0.858 & 0.876 & 0.843 & 0.814 & 0.775 & 0.828 \\
\hline 1984 & 0.790 & 0.663 & 0.712 & 0.647 & 0.754 & 0.775 & 0.694 & 0.727 & 0.779 & 0.556 & 0.706 \\
\hline 1985 & 0.742 & 0.705 & 0.717 & 0.720 & 0.750 & 0.770 & 0.710 & 0.757 & 0.758 & 0.631 & 0.725 \\
\hline 1986 & 0.803 & 0.613 & 0.711 & 0.789 & 0.790 & 0.791 & 0.615 & 0.685 & 0.821 & 0.518 & 0.706 \\
\hline 1987 & 0.857 & 0.528 & 0.768 & 0.730 & 0.763 & 0.829 & 0.687 & 0.671 & 0.849 & 0.394 & 0.691 \\
\hline 1988 & 0.871 & 0.557 & 0.832 & 0.778 & 0.843 & 0.838 & 0.723 & 0.604 & 0.853 & 0.425 & 0.715 \\
\hline 1989 & 0.715 & 0.590 & 0.791 & 0.745 & 0.741 & 0.705 & 0.580 & 0.666 & 0.692 & 0.612 & 0.680 \\
\hline 1990 & 0.748 & 0.647 & 0.748 & 0.699 & 0.746 & 0.739 & 0.606 & 0.677 & 0.720 & 0.646 & 0.696 \\
\hline 1991 & 0.685 & 0.650 & 0.713 & 0.679 & 0.738 & 0.738 & 0.581 & 0.644 & 0.751 & 0.541 & 0.669 \\
\hline 1992 & 0.638 & 0.573 & 0.617 & 0.550 & 0.627 & 0.636 & 0.470 & 0.535 & 0.599 & 0.357 & 0.553 \\
\hline 1993 & 0.686 & 0.745 & 0.756 & 0.653 & 0.743 & 0.659 & 0.566 & 0.644 & 0.649 & 0.595 & 0.667 \\
\hline 1994 & 0.618 & 0.583 & 0.621 & 0.567 & 0.653 & 0.577 & 0.502 & 0.520 & 0.593 & 0.470 & 0.568 \\
\hline 1995 & 0.616 & 0.567 & 0.610 & 0.589 & 0.605 & 0.567 & 0.466 & 0.498 & 0.584 & 0.490 & 0.557 \\
\hline 1996 & 0.612 & 0.529 & 0.532 & 0.506 & 0.558 & 0.550 & 0.427 & 0.385 & 0.557 & 0.444 & 0.505 \\
\hline 1997 & 0.584 & 0.535 & 0.513 & 0.464 & 0.579 & 0.551 & 0.425 & 0.425 & 0.538 & 0.411 & 0.499 \\
\hline 1998 & 0.648 & 0.511 & 0.512 & 0.436 & 0.526 & 0.540 & 0.406 & 0.364 & 0.524 & 0.363 & 0.475 \\
\hline 1999 & 0.784 & 0.535 & 0.456 & 0.496 & 0.499 & 0.521 & 0.365 & 0.445 & 0.548 & 0.387 & 0.493 \\
\hline 2000 & 0.601 & 0.312 & 0.409 & 0.373 & 0.467 & 0.431 & 0.299 & 0.362 & 0.480 & 0.263 & 0.389 \\
\hline 2001 & 0.732 & 0.388 & 0.476 & 0.427 & 0.566 & 0.485 & 0.392 & 0.367 & 0.563 & 0.317 & 0.458 \\
\hline \multicolumn{12}{|c|}{ Annual change rate } \\
\hline & & 0.951 & 0.962 & 0.956 & 0.970 & 0.963 & 0.952 & 0.949 & 0.970 & 0.941 & 0.960 \\
\hline
\end{tabular}


Table A1. DEA Efficiencies in Cross- Section DEA by Year

\begin{tabular}{|c|c|c|c|c|c|c|c|c|c|c|}
\hline \multirow[t]{2}{*}{ Year } & \multicolumn{10}{|c|}{ Firm } \\
\hline & Taked & Sankyo & $\begin{array}{l}\text { Yama } \\
\text { nouchi }\end{array}$ & Daiichi & Eisai & $\begin{array}{l}\text { Shio- } \\
\text { nogi }\end{array}$ & $\begin{array}{l}\text { Fuji- } \\
\text { sawa }\end{array}$ & Chugai & Tanabe & $\begin{array}{l}\text { Yoshi- } \\
\text { tomi }\end{array}$ \\
\hline 1982 & 0.80 & 1 & 0.89 & 0.67 & 0.74 & 0.87 & 0.84 & 0.81 & 0.86 & 0.67 \\
\hline 1983 & 0.84 & 1 & 0.89 & 0.78 & 0.74 & 0.88 & 0.79 & 1 & 0.93 & 0.57 \\
\hline 1984 & 0.83 & 1 & 1 & 0.91 & 0.69 & 0.97 & 1 & 0.91 & 0.93 & 0.84 \\
\hline 1985 & 0.90 & 1 & 1 & 1 & 0.62 & 0.80 & 0.72 & 0.83 & 0.86 & 0.65 \\
\hline 1986 & 0.81 & 1 & 0.94 & 1 & 0.67 & 0.82 & 1 & 0.83 & 1 & 0.65 \\
\hline 1987 & 0.85 & 1 & 1 & 1 & 0.63 & 0.78 & 0.78 & 0.69 & 1 & 0.98 \\
\hline 1988 & 0.80 & 1 & 1 & 0.91 & 0.60 & 0.76 & 0.86 & 0.68 & 1 & 1 \\
\hline 1989 & 0.84 & 1 & 1 & 1 & 0.72 & 0.83 & 0.94 & 0.60 & 0.88 & 1 \\
\hline 1990 & 0.74 & 1 & 1 & 0.90 & 0.64 & 0.72 & 0.84 & 0.55 & 0.84 & 1 \\
\hline 1991 & 0.72 & 1 & 0.97 & 0.80 & 0.61 & 0.65 & 0.84 & 0.63 & 0.78 & 1 \\
\hline 1992 & 0.77 & 1 & 0.92 & 0.88 & 0.67 & 0.72 & 1 & 0.69 & 0.96 & 1 \\
\hline 1993 & 0.82 & 1 & 0.86 & 0.83 & 0.68 & 0.78 & 0.84 & 0.72 & 0.94 & 1 \\
\hline 1994 & 0.83 & 1 & 0.98 & 0.94 & 0.78 & 0.93 & 0.96 & 0.84 & 1 & 1 \\
\hline 1995 & 1 & 1 & 1 & 0.92 & 0.83 & 0.94 & 1 & 0.81 & 0.94 & 0.99 \\
\hline 1996 & 1 & 1 & 1 & 0.94 & 0.88 & 0.94 & 1 & 0.91 & 0.95 & 0.89 \\
\hline 1997 & 1 & 1 & 1.00 & 0.89 & 0.68 & 0.85 & 0.89 & 0.60 & 0.99 & 1 \\
\hline 1998 & 1 & 1 & 0.69 & 0.88 & 0.58 & 0.84 & 0.81 & 0.74 & 0.90 & 1 \\
\hline 1999 & 1 & 0.93 & 1 & 0.98 & 0.75 & 1 & 0.86 & 0.61 & 1 & 0.93 \\
\hline 2000 & 1 & 0.81 & 0.74 & 0.83 & 0.65 & 0.79 & 0.63 & 0.51 & 1 & 0.95 \\
\hline 2001 & 1 & 0.65 & 0.67 & 0.79 & 0.60 & 0.83 & 0.50 & 0.51 & 1 & 0.67 \\
\hline
\end{tabular}


Table A2. DEA Efficiencies in Time Series DEA by Firm

\begin{tabular}{|c|c|c|c|c|c|c|c|c|c|c|}
\hline \multirow[t]{2}{*}{ Year } & \multicolumn{10}{|c|}{ Firm } \\
\hline & Takeda & Sankyo & $\begin{array}{l}\text { Yama } \\
\text { nouchi }\end{array}$ & Daiichi & Eisai & $\begin{array}{l}\text { Shio- } \\
\text { nogi }\end{array}$ & $\begin{array}{l}\text { Fuji- } \\
\text { sawa }\end{array}$ & Chugai & Tanabe & $\begin{array}{l}\text { Yoshi- } \\
\text { tomi }\end{array}$ \\
\hline 1982 & 1 & 1 & 1 & 1 & 1 & 1 & 1 & 0.97 & 1.00 & 1 \\
\hline 1983 & 1 & 0.89 & 0.98 & 0.92 & 0.94 & 0.88 & 0.91 & 1 & 1 & 0.81 \\
\hline 1984 & 0.90 & 0.84 & 0.94 & 0.89 & 0.88 & 1 & 1 & 1 & 0.90 & 0.73 \\
\hline 1985 & 0.86 & 0.82 & 0.91 & 1 & 0.83 & 0.79 & 0.77 & 0.84 & 0.87 & 0.65 \\
\hline 1986 & 0.84 & 0.79 & 0.85 & 1 & 0.87 & 0.79 & 0.95 & 0.86 & 0.97 & 0.62 \\
\hline 1987 & 0.94 & 0.74 & 0.99 & 1 & 0.82 & 0.76 & 0.74 & 0.74 & 1 & 0.61 \\
\hline 1988 & 0.90 & 0.77 & 1 & 1 & 0.84 & 0.76 & 0.85 & 0.66 & 1 & 0.65 \\
\hline 1989 & 0.77 & 0.72 & 0.86 & 0.92 & 0.80 & 0.74 & 0.76 & 0.64 & 0.73 & 0.93 \\
\hline 1990 & 0.69 & 0.77 & 0.78 & 0.80 & 0.80 & 0.65 & 0.76 & 0.60 & 0.73 & 1 \\
\hline 1991 & 0.64 & 0.84 & 0.77 & 0.75 & 0.79 & 0.59 & 0.66 & 0.66 & 0.71 & 0.82 \\
\hline 1992 & 0.66 & 0.89 & 0.80 & 0.78 & 0.79 & 0.61 & 0.58 & 0.71 & 0.71 & 0.65 \\
\hline 1993 & 0.78 & 0.96 & 0.78 & 0.76 & 0.80 & 0.63 & 0.66 & 0.71 & 0.71 & 0.92 \\
\hline 1994 & 0.63 & 0.83 & 0.77 & 0.73 & 0.79 & 0.66 & 0.62 & 0.72 & 0.70 & 0.86 \\
\hline 1995 & 0.74 & 0.74 & 0.79 & 0.72 & 0.79 & 0.67 & 0.72 & 0.66 & 0.64 & 0.89 \\
\hline 1996 & 0.74 & 0.92 & 0.81 & 0.75 & 0.88 & 0.67 & 0.55 & 0.60 & 0.66 & 0.97 \\
\hline 1997 & 0.73 & 1.00 & 0.80 & 0.71 & 0.77 & 0.62 & 0.51 & 0.51 & 0.68 & 1 \\
\hline 1998 & 0.82 & 1 & 0.52 & 0.68 & 0.60 & 0.61 & 0.48 & 0.48 & 0.64 & 1 \\
\hline 1999 & 0.96 & 0.86 & 0.53 & 0.70 & 0.58 & 0.68 & 0.40 & 0.46 & 0.67 & 0.84 \\
\hline 2000 & 0.94 & 0.50 & 0.55 & 0.62 & 0.82 & 0.56 & 0.31 & 0.44 & 0.82 & 0.78 \\
\hline 2001 & 1 & 0.46 & 0.48 & 0.56 & 0.81 & 0.53 & 0.31 & 0.40 & 0.81 & 0.57 \\
\hline
\end{tabular}


Table A3. DEA Efficiencies in Panel DEA

\begin{tabular}{|c|c|c|c|c|c|c|c|c|c|c|}
\hline \multirow[t]{2}{*}{ Year } & \multicolumn{10}{|c|}{ Firm } \\
\hline & Takeda & Sankyo & $\begin{array}{l}\text { Yama } \\
\text { nouchi }\end{array}$ & Daiichi & Eisai & $\begin{array}{l}\text { Shio- } \\
\text { nogi }\end{array}$ & $\begin{array}{l}\text { Fuji- } \\
\text { sawa }\end{array}$ & Chugai & Tanabe & $\begin{array}{l}\text { Yoshi- } \\
\text { tomi }\end{array}$ \\
\hline 1982 & 0.76 & 1 & 0.82 & 0.67 & 0.64 & 0.83 & 0.81 & 0.73 & 0.78 & 0.65 \\
\hline 1983 & 0.71 & 0.89 & 0.74 & 0.62 & 0.58 & 0.73 & 0.71 & 0.78 & 0.72 & 0.45 \\
\hline 1984 & 0.65 & 0.84 & 0.74 & 0.60 & 0.49 & 0.74 & 0.63 & 0.69 & 0.70 & 0.46 \\
\hline 1985 & 0.65 & 0.82 & 0.68 & 0.70 & 0.46 & 0.64 & 0.49 & 0.59 & 0.65 & 0.39 \\
\hline 1986 & 0.64 & 0.79 & 0.71 & 0.87 & 0.52 & 0.64 & 0.54 & 0.60 & 0.81 & 0.34 \\
\hline 1987 & 0.73 & 0.74 & 0.95 & 0.94 & 0.51 & 0.63 & 0.58 & 0.54 & 0.85 & 0.37 \\
\hline 1988 & 0.69 & 0.77 & 1 & 0.89 & 0.53 & 0.63 & 0.67 & 0.44 & 0.84 & 0.41 \\
\hline 1989 & 0.59 & 0.72 & 0.81 & 0.81 & 0.50 & 0.59 & 0.51 & 0.43 & 0.59 & 0.67 \\
\hline 1990 & 0.53 & 0.76 & 0.73 & 0.67 & 0.47 & 0.52 & 0.46 & 0.40 & 0.58 & 0.73 \\
\hline 1991 & 0.47 & 0.81 & 0.70 & 0.62 & 0.47 & 0.47 & 0.44 & 0.44 & 0.58 & 0.56 \\
\hline 1992 & 0.51 & 0.83 & 0.72 & 0.62 & 0.48 & 0.49 & 0.45 & 0.47 & 0.58 & 0.36 \\
\hline 1993 & 0.52 & 0.87 & 0.68 & 0.61 & 0.48 & 0.51 & 0.45 & 0.47 & 0.56 & 0.61 \\
\hline 1994 & 0.49 & 0.76 & 0.69 & 0.62 & 0.49 & 0.53 & 0.46 & 0.48 & 0.57 & 0.51 \\
\hline 1995 & 0.57 & 0.67 & 0.70 & 0.61 & 0.50 & 0.53 & 0.42 & 0.44 & 0.53 & 0.53 \\
\hline 1996 & 0.60 & 0.83 & 0.73 & 0.67 & 0.54 & 0.54 & 0.43 & 0.40 & 0.55 & 0.58 \\
\hline 1997 & 0.55 & 0.92 & 0.72 & 0.60 & 0.47 & 0.50 & 0.40 & 0.34 & 0.55 & 0.62 \\
\hline 1998 & 0.70 & 0.95 & 0.52 & 0.58 & 0.38 & 0.49 & 0.38 & 0.33 & 0.53 & 0.59 \\
\hline 1999 & 0.86 & 0.80 & 0.51 & 0.64 & 0.36 & 0.49 & 0.27 & 0.33 & 0.54 & 0.50 \\
\hline 2000 & 0.93 & 0.45 & 0.55 & 0.58 & 0.45 & 0.45 & 0.24 & 0.33 & 0.65 & 0.45 \\
\hline 2001 & 0.99 & 0.41 & 0.48 & 0.52 & 0.44 & 0.43 & 0.24 & 0.27 & 0.62 & 0.33 \\
\hline
\end{tabular}

